\title{
A variational approach for retrieving ice cloud properties from infrared measurements: application in the context of two IIR validation campaigns
}

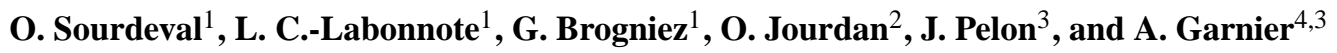 \\ ${ }^{1}$ LOA, UMR8518, CNRS - Université Lille1, Villeneuve d'Ascq, France \\ ${ }^{2}$ LaMP, Université Blaise Pascal, Clermont-Ferrand, France \\ ${ }^{3}$ LATMOS, UPMC-UVSQ-CNRS, Paris, France \\ ${ }^{4}$ Science Systems and Applications Inc., NASA/LaRC, Hampton, VA, USA \\ Correspondence to: O. Sourdeval (odran.sourdeval@uni-leipzig.de)
}

Received: 25 January 2013 - Published in Atmos. Chem. Phys. Discuss.: 27 February 2013

Revised: 27 June 2013 - Accepted: 8 July 2013 - Published: 21 August 2013

\begin{abstract}
Cirrus are cloud types that are recognized to have a strong impact on the Earth-atmosphere radiation balance. This impact is however still poorly understood, due to the difficulties in describing the large variability of their properties in global climate models. Consequently, numerous airborne and space-borne missions have been dedicated to their study in the last decades. The satellite constellation A-Train has for instance proven to be particularly helpful for the study of cirrus. More particularly, the Infrared Imaging Radiometer (IIR) carried onboard the Cloud-Aerosol Lidar and Infrared Pathfinder Satellite Observation (CALIPSO) satellite shows a great sensitivity to the radiative and microphysical properties of these clouds. Our study presents a novel methodology that uses the thermal infrared measurements of IIR to retrieve the ice crystal effective size and optical thickness of cirrus. This methodology is based on an optimal estimation scheme, which possesses the advantage of attributing precise uncertainties to the retrieved parameters. Two IIR airborne validation campaigns have been chosen as case studies for illustrating the results of our retrieval method. It is observed that optical thicknesses could be accurately retrieved but that large uncertainties may occur on the effective diameters. Strong agreements have also been found between the products of our method when separately applied to the measurements of IIR and of the airborne radiometer CLIMAT-AV, which consolidates the results of previous validation studies of IIR level1 measurements. Comparisons with in situ observations and with operational products of IIR are also discussed and ap-
\end{abstract}

pear to be coherent with our results. However, we have found that the quality of our retrievals can be strongly impacted by uncertainties related to the choice of a pristine crystal model and by poor constraints on the properties of possible liquid cloud layers underneath cirrus. Simultaneous retrievals of liquid clouds radiative and microphysical properties and/or the use of different ice crystal models should therefore be considered in order to improve the quality of the results.

\section{Introduction}

Cirrus are ice clouds that are situated in the high troposphere, and recognized to have a major impact on the Earthatmosphere radiation balance (Liou, 1986; Stephens et al., 1990; Lohmann et al., 1995; Lynch et al., 2002). They are composed of ice crystals with highly complex habits, which implies the necessity to deal with large ranges of microphysical, optical, and geometrical properties in order to account for their radiative effect (Baran, 2009). The study of cirrus has, for these reasons, become one of the main objectives of the World Climate Research Program (WCRP, 1986). Nevertheless, the radiative impact of clouds remains one of the largest source of uncertainties on climate model estimates (Forster et al., 2007). More particularly, the large variability of cirrus properties can lead to difficulties in quantifying the balance between their albedo and greenhouse effects (e.g. Zhang et al., 1999; Fusina et al., 2007). It is 
therefore important to observe these clouds and to develop methods dedicated to a precise quantification of their microand macro-physical structure in order to supply accurate information to climate models.

In this context, many airborne campaigns have been undertaken to successfully improve our understanding of cirrus (e.g. FIRE Ackerman et al., 1990; ICE Raschke et al., 1990; EUCREX Sauvage et al., 1999; FRENCH Brogniez et al., 2004; ACTIVE Vaughan et al., 2005a; CIRCLE-2 Mioche et al., 2010; Sourdeval et al., 2012; or TC ${ }^{4}$ King et al., 2010). Databases constituted during such campaigns have become extremely valuable for the development of models describing the microphysical and optical properties of these clouds (e.g. Baran et al., 2009; Yang et al., 2005; Baum et al., 2011). These campaigns are nevertheless too scarce to fully represent cirrus all over the globe, and a combined use of satellite observations therefore appears necessary to obtain quantitative global records of cirrus properties.

Since the launch of its first satellites in 2002, the A-Train constellation has greatly contributed to the study of the Earth and its atmosphere by providing all kinds of measurements and products. These contributions have become even more constructive since 2006, with the participation of the CloudAerosol Lidar and Infrared Pathfinder Satellite Observations (CALIPSO) and CloudSat, which are more directly dedicated to the study of clouds and aerosols. Indeed, instruments such as the Cloud-Aerosol Lidar with Orthogonal Polarization (CALIOP) (measuring at $532 \mathrm{~nm}$ and $1024 \mathrm{~nm}$ ) and the Infrared Imaging Radiometer (IIR) (measuring in three narrow band channels centered at $8.65,10.60$, and 12.05- $\mu \mathrm{m}$ ) onboard CALIPSO can provide accurate information on cirrus position, optical thickness, extinction profile, and diverse crystal habits (e.g. Garnier et al., 2012; Vaughan et al., 2009; Winker et al., 2010). Along with these new possible synergies, the use of optimal estimation has become common in retrieval algorithms. This method appears to be highly efficient for dealing with a large number of measurements in order to retrieve very different kinds of parameters. Delanoë and Hogan (2010), for instance, showed that this technique can be successfully applied to retrieve accurate profiles of cirrus properties from measurements of IIR, CALIOP and the 94-GHz Cloud Profiler Radar (CPR) onboard CloudSat.

In a study by Sourdeval et al. (2012), CIRrus Cloud Experiment (CIRCLE)-2 and Biscay '08 were presented as two airborne validation campaigns of IIR. This study allowed an unambiguous validation of IIR level-1 measurements in clearsky areas, but denoted difficulties in achieving comparisons of radiometric measurements in cloudy areas due to a lack of precise knowledge of cirrus properties. The present paper therefore aims to consolidate the results of this previous study by showing that similar cirrus properties can be independently retrieved from IIR and CLIMAT-AV measurements. To perform the retrievals, a variational scheme based on a bayesian approach and a Levenberg-Marquardt minimization method has been used for both instruments. The retrievals are later validated through comparisons with IIR operational products and with in situ estimates obtained during CIRCLE-2.

Section 2 of this paper introduces the general context of this study by briefly describing the instruments, the validation campaigns, and the main results of the aforementioned study by Sourdeval et al. (2012). Section 3 presents the retrieval methodology, together with a summary of the theoretical approach. The non-retrieved parameters used in the forward model are also listed, along with their uncertainties. Finally, the results of the retrievals are discussed and analyzed in Sect. 4, where three days of CIRCLE-2 and Biscay '08 are taken as case studies. Comparisons of these retrievals with operational products of IIR and with in situ estimates are also shown and discussed.

\section{The CIRCLE-2 and Biscay '08 campaigns}

The two airborne campaigns CIRCLE-2 and Biscay '08 were conducted with the principal objective to validate measurements of space-borne instruments, such as the Infrared Imaging Radiometer (IIR) (Corlay et al., 2000). This radiometer is carried onboard CALIPSO together with the Cloud-Aerosol Lidar with Orthogonal Polarization (CALIOP) and the Wide Field Camera (WFC). It performs radiative measurements in three spectral bands within the infrared atmospheric window (centered at $8.65,10.60$, and $12.05 \mu \mathrm{m}$, with about $1 \mu \mathrm{m}$ of full width at half maximum). The swath of IIR is about $64 \mathrm{~km}$ with a pixel size of $1 \mathrm{~km}$.

CIRCLE-2 and Biscay ' 08 took place during the periods of 12 to 26 May 2007 and 2 September to 18 October 2008, respectively. Both campaigns involved a Falcon-20 aircraft (hereafter referred to as FF20) that performed remote sensing measurements over cloud decks. This aircraft was equipped by the SAFIRE ("Service des Avions Français Instrumentés pour la Recherche en Environnement") with the Conveyable Low-noise Infrared radiometer for Measurements of Atmosphere and ground surface Targets (CLIMAT)-Airborne Version (AV) (Brogniez et al., 2003), and the Lidar "pour l'Etude des interactions Aérosols Nuages Dynamique Rayonnement et du cycle de l'Eau" (LEANDRE)-New Generation (NG). It is important to note that the spectral characteristics of CLIMAT-AV are highly similar to the ones of IIR. The CIRCLE-2 campaign also involved a second aircraft (hereafter called GF20) equipped by the DLR ("Deutsches Zentrum für Luft- und Raumfahrt") with instruments dedicated to perform in situ measurements of cirrus decks, such as a Cloud Particle Imager (CPI) (Lawson et al., 2001), a PMS FSSP-300 (Knollenberg, 1976), and a Polar Nephelometer probe (Gayet et al., 1997). During each campaign day, the flights took place right under the track of CALIPSO. However, only three days met the optimal conditions, i.e. an acceptable space and time collocation with CALIPSO, necessary for our validation studies: 16 and 25 May 2007 and 
18 October 2008. During these days, the measurements were mostly performed over the Atlantic ocean in the Bay of Biscay. Further details on the instruments and the flight tracks are described in detail by Mioche et al. (2010) and Sourdeval et al. (2012), and in the Sect. 5 of this paper.

The study by Sourdeval et al. (2012) presents direct comparisons between brightness temperatures simultaneously measured by IIR and CLIMAT-AV during the three "optimal" campaign days. These comparisons showed strong similarities, yet small deviations could be observed between the measurements made by both instruments, especially in their 8.6$\mu \mathrm{m}$ channels. To explain these deviations, a radiative transfer code was used to simulate brightness temperatures in clear sky areas. An analysis of these simulations showed that the deviations could be explained by slight dissimilarities between the spectral bands of both instruments and by the fact that one part of the atmosphere (above the aircraft) was seen by IIR and not by CLIMAT-AV. Overall, these results allowed validating the level-1 measurements of the spaceborne radiometer. The authors nevertheless pointed out some difficulties in applying the same methodology in the presence of cirrus, as a precise knowledge of their properties is necessary for effectuating brightness temperature simulations. This paper therefore seeks to consolidate the validation of IIR level-1 measurement by showing that coherent retrievals of ice cloud properties can be obtained when applying our retrieval method to the measurements of CLIMAT-AV and IIR.

\section{Description of the methodology}

\subsection{Discussion of the retrieval approach}

This section introduces the variational scheme used in the present study. It follows an optimal estimation method, with the aim of retrieving the optical thickness and ice crystal effective size of cirrus. The choice of the method was determined by its clear treatment of experimental errors, which is made possible by using a rigorous mathematical framework. It also, on a general note, shows great flexibility in treating the synergy of different kinds of measurements. Similar variational schemes have already been successfully applied to measurements of A-Train instruments in order to retrieve cirrus properties (Cooper et al., 2007; Delanoë and Hogan, 2010).

The optimal estimation method is based on a bayesian approach. It takes advantage of a formalism that uses probability density functions to link the measurement vector space with the state vector space (formed by the parameters to be retrieved), together with their uncertainties. This powerful method allows finding a solution that is most likely to be consistent with the measurements and any given a priori knowledge, within their uncertainties. Further, optimal estimation is perfectly appropriate for posterior analyses of errors linked to the non-retrieved parameters and for prior analyses of information content (Shannon and Weaver, 1949). Such analyses are extremely useful for characterizing the theoretical amount of information contained in different kinds of measurements, which is important for understanding and improving the quality of the retrievals (Cooper et al., 2003, 2006; L'Ecuyer et al., 2006). A thorough development of the theory is widely available in the preceding literature, and thus the following section only briefly summarizes how optimal estimation is applied in this study. The following parts respect the approach and formalism developed by Rodgers (2000) for the application of inverse methods to atmospheric problems.

\subsection{Application of optimal estimation study}

The result of any measurement can generally be described by Eq. (1), where $\boldsymbol{x}$ and $\boldsymbol{y}$ represent the state and the measurement vectors, respectively. The function $F$ expresses the link between these two vectors and is called the forward model. In this study, it is comparable to the radiative transfer model. Lastly, $\epsilon$ defines the errors that result from the measurements and from the forward model. In retrieval schemes, this equation is thus inverted in order to retrieve $\boldsymbol{x}$ from the information provided by $\boldsymbol{y}$, with respect to the errors defined by $\boldsymbol{\epsilon}$.

$\boldsymbol{y}=F(\boldsymbol{x})+\boldsymbol{\epsilon}$

It is today widely known that measurements within the infrared atmospheric window are well adapted for retrieving ice cloud properties (e.g. Inoue, 1985; Parol et al., 1991). More particularly, Dubuisson et al. (2008) have shown that IIR channels are highly sensitive to the cirrus optical thickness, and in a lesser extent to the ice crystal effective size. Consequently, the state $(\boldsymbol{x})$ and measurement $(\boldsymbol{y})$ vectors used in this study are thus defined as

$\boldsymbol{x}=\left(\begin{array}{c}D_{\mathrm{eff}} \\ \tau\end{array}\right), \quad$ and $\quad \boldsymbol{y}=\left(\begin{array}{c}R_{08} \\ R_{10} \\ R_{12}\end{array}\right)$,

where the components $R_{08}, R_{10}$, and $R_{12}$ correspond to the radiances measured by IIR or CLIMAT-AV in their channels centered at $8.65,10.60$, and $12.05 \mu \mathrm{m}$, respectively. These channels are hereafter referred to as $\mathrm{C} 08, \mathrm{C} 10$, and $\mathrm{C} 12$. In the state vector, $\tau$ corresponds to the cirrus extinction optical thickness at $12.05 \mu \mathrm{m}$ and $D_{\text {eff }}$ is the effective diameter, which corresponds to the ratio between the volume $V(L)$ and the projected area $A(L)$ of a crystal of maximum length $L$ (Grenfell and Warren, 1999; Mitchell, 2002). For a pristine crystal following a size distribution $n(L)$, the effective diameter can thus be defined as

$D_{\text {eff }}=\frac{3}{2} \frac{\int_{L} V(L) n(L) \mathrm{d} L}{\int_{L} A(L) n(L) \mathrm{d} L}$. 
The optimal estimation method requires the use of a socalled a priori state vector $\boldsymbol{x}_{a}$, shown by Eq. (4). This vector corresponds to the prior knowledge of the state vector, i.e. before the measurements have been made. The sizes of ice crystals in mid-latitude cirrus supposedly ranging between 20 and $100 \mu \mathrm{m}$ (Gayet et al., 2004), $D_{\operatorname{eff} a}$ has been set to $50 \mu \mathrm{m}$ for the rest of the study. The other component, $\tau_{a}$, is set to 1.0 in order to be representative of thin cirrus (Sassen and Cho, 1992). These values can however be taken approximately since very large uncertainties are attributed to each of them, as explained in the next paragraph.

$\boldsymbol{x}_{a}=\left(\begin{array}{c}D_{\operatorname{eff} a} \\ \tau_{a}\end{array}\right)$

In order to take the different sources of uncertainties into account, $\boldsymbol{x}_{\boldsymbol{a}}$ and $\boldsymbol{y}$ are each related to an error covariance matrix. We thus call the error covariance matrices related to the a priori state vector and to the measurement vector $\mathbf{S}_{a}$ and $\mathbf{S}_{y}$, respectively. Additionally, the matrix $\mathbf{S}_{f}$ also needs to be considered. It represents the global errors assigned to the forward model because of uncertainties attached to its non-retrieved parameters (e.g. atmospheric profiles, liquid cloud properties, etc...). The two matrices $\mathbf{S}_{f}$ and $\mathbf{S}_{y}$ can be summed in order to form the total error covariance matrix, called $\mathbf{S}_{\epsilon}$. The hypothesis that each component inside the measurement or state vectors is independent from one another is accepted in this study. It implies that the covariance matrices $\mathbf{S}_{a}, \mathbf{S}_{y}$, and $\mathbf{S}_{f}$ are diagonal as expressed by Eq. (5a) and (5b). This hypothesis is generally adopted in optimal estimation schemes due to the difficulties connected with clear identification of correlations between the parameters.

$$
\begin{aligned}
& \mathbf{S}_{a}=\left(\begin{array}{cc}
\sigma_{D_{\mathrm{eff} a}}^{2} & 0 \\
0 & \sigma_{\tau_{a}}^{2}
\end{array}\right) \\
& \mathbf{S}_{\epsilon}=\mathbf{S}_{y}+\mathbf{S}_{f}
\end{aligned}
$$

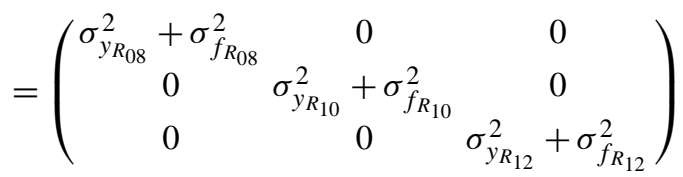

$$
\begin{aligned}
& =\left(\begin{array}{ccc}
\sigma_{\epsilon_{R_{08}}}^{2} & 0 & 0 \\
0 & \sigma_{\epsilon_{R_{10}}}^{2} & 0 \\
0 & 0 & \sigma_{\epsilon_{R_{12}}}^{2}
\end{array}\right)
\end{aligned}
$$

Because the retrievals need to be mainly dependent on the measurement and not on any a priori considerations, large errors are intentionally attributed to each component of the a priori state vector. The diagonal components of $\mathbf{S}_{y}$, i.e. $\sigma_{y_{R}}^{2}$, are directly obtained from the instrumental accuracy of CLIMAT-AV or IIR in each channel, centered at $\lambda$. The diagonal components of $\mathbf{S}_{f}$, i.e. $\sigma_{f_{R_{\lambda}}}^{2}$, are defined as

$\sigma_{f_{R_{\lambda}}}^{2}=\sum_{i=1}^{N} \sigma_{f_{Z_{i}, \lambda}}^{2}$, where $N$ is the number of non-retrieved parameters used in the forward model and $\sigma_{f_{i}, \lambda}$ is the standard deviation attributed to each non-retrieved parameter $Z_{i}$. This standard deviation is given by the sensitivity of the forward model to $Z_{i}$, pondered by the a priori knowledge $\epsilon_{Z_{i}}$ of this parameter, as described by Eq. (6b).

$\sigma_{f_{Z_{i}, \lambda}}=\frac{\partial F_{\lambda}}{\partial Z_{i}} \epsilon_{Z_{i}}$

More details on the instrumental accuracy and the nonretrieved parameter used in the forward model will be given in Sect. 3.3.

Finally, under the assumption of gaussian statistics, the optimal estimation of the state vector $(\hat{\boldsymbol{x}})$ is found by minimizing the scalar cost function $\phi$ :

$$
\begin{aligned}
\phi= & {[\boldsymbol{y}-F(\boldsymbol{x})]^{T} \mathbf{S}_{\epsilon}^{-1}[\boldsymbol{y}-F(\boldsymbol{x})]+} \\
& {\left[\boldsymbol{x}-\boldsymbol{x}_{a}\right]^{T} \mathbf{S}_{a}{ }^{-1}\left[\boldsymbol{x}-\boldsymbol{x}_{a}\right] . }
\end{aligned}
$$

Because the forward model is non-linear, a LevenbergMarquardt approach (Marquardt, 1963) is used in order to find the best estimate of the state vector that minimizes the cost function $\phi$. The iterative formula is expressed as

$$
\begin{aligned}
\boldsymbol{x}_{i+1}= & \boldsymbol{x}_{i}+\left[(1+\gamma) \mathbf{S}_{a}^{-1}+\mathbf{K}_{i}^{T} \mathbf{S}_{\epsilon}^{-1} \mathbf{K}_{i}\right]^{-1} \\
& \left\{\mathbf{K}_{i}^{T} \mathbf{S}_{\epsilon}^{-1}\left[\boldsymbol{y}-F\left(\boldsymbol{x}_{i}\right)\right]-\mathbf{S}_{a}^{-1}\left[\boldsymbol{x}_{i}-\boldsymbol{x}_{a}\right]\right\},
\end{aligned}
$$

where $\gamma$ is the "regularization coefficient" of the LevenbergMarquardt approach $\phi$ (Fletcher, 1971). K represents the weighting (or kernel) matrix, which contains the sensitivity of each measurement channel to each component of the state vector, and is defined as

$\mathbf{K}=\left(\begin{array}{ll}\frac{\partial R_{08}}{\partial D_{\text {eff }}} & \frac{\partial R_{08}}{\partial \tau} \\ \frac{\partial R_{10}}{\partial D_{\text {eff }}} & \frac{\partial R_{10}}{\partial \tau} \\ \frac{\partial R_{12}}{\partial D_{\text {eff }}} & \frac{\partial R_{12}}{\partial \tau}\end{array}\right)$.

In the case of large uncertainties attributed to the components of the a priori state vector, Eq. (7) shows that the minimization is achieved when the best estimate of the state vector allows the forward model to be "close enough" to the measurements. By "close enough" we mean that the distance between the forward model and the measurements can be explained by the uncertainties. Marks and Rodgers (1993) showed that a good coherence can be confidently concluded between the forward model and the measurements if the value of the cost function is lesser than the dimension of the measurement vector.

Finally, the a priori and general error covariance matrices are used, together with the weighting matrix, for the calculation of the error covariance matrix of the posterior state vector $\mathbf{S}_{x}$, as shown by Eq. (10). This matrix identifies the errors ascribed to each retrieved parameter.

$\mathbf{S}_{x}=\left(\mathbf{K}^{T} \mathbf{S}_{\epsilon}^{-1} \mathbf{K}+\mathbf{S}_{a}^{-1}\right)^{-1}$ 


\subsection{Non-retrieved parameters characterization and accuracy}

One of the advantages of optimal estimation lays in that it takes into account the errors related to each non-retrieved parameter and to the instrumental accuracy in order to provide accurate uncertainties on the retrievals. The following subsections therefore discuss the non-retrieved parameters used in our forward model, along with their accuracies (which correspond to the term $\epsilon_{Z_{i}}$ in Eq. 6b).

\subsubsection{Radiative transfer model}

In this study, the forward model is represented by the FASt Discrete Ordinate Method (FASDOM) radiative transfer code developed by Dubuisson et al. (2005). The atmosphere is therefore considered plane-parallel and is divided in $1 \mathrm{~km}$-thick homogeneous layers, from the surface to $30 \mathrm{~km}$ of altitude. If a layer contains a cloud, it is subdivided in $100 \mathrm{~m}$ sublayers for a better accuracy of the cloud positioning. FASDOM takes into account the scattering and absorption effects of clouds and of atmospheric gases in order to simulate accurate radiances in each of the IIR and CLIMAT-AV spectral bands. Multiple scattering processes are also treated. The radiances simulated by FASDOM have shown an accuracy better than $0.6 \%$ in each channel when compared with a high spectral resolution line-by-line code (Dubuisson et al., 1996, 2005).

\subsubsection{Atmospheric profiles}

The computation of infrared radiances by FASDOM requires knowledge of the pressure, temperature, specific humidity, and ozone concentration in each layer. In order to make accurate comparisons with the official IIR products, these profiles are directly extracted from CALIOP Level-2 data products, provided by the GOES-5 atmospheric model of the Global Modeling and Assimilation Office (GMAO) (Rienecker et al., 2008). The uncertainties attached to these products are however not directly provided. Consequently the error attributed to each profile parameter is based on the known accuracy of AIRS/AMSU-A/HSB EOS products from Aqua (Parkinson and Greenstone, 2000) that are used in the GMAO re-analysis. An error of $1 \mathrm{~K}$ and a relative error of $20 \%$ are thus assigned to each layer of the temperature and relative humidity profiles, respectively. The accuracy of the ozone profile is considered to be $10 \%$ of the total ozone column burden.

\subsubsection{Surface properties}

During the CIRCLE-2 campaign, all measurements were made over the Atlantic ocean. During Biscay '08, part of the measurements occurred over Spain. This part, however, coincides with the presence of an extremely thick cirrus deck (Sourdeval et al., 2012), and therefore the difference of surface type should have no major impact on retrievals in this area. Consequently, the surface is always considered as oceanic in this study. Three values of seawater emissivity calculated for IIR spectral bands are used: 0.9838, 0.9903, and 0.9857 for the channels $\mathrm{C} 08, \mathrm{C} 10$, and $\mathrm{C} 12$, respectively (Wilber et al., 1999). A reasonable uncertainty of $1 \%$ is attributed to the emissivity in each channel.

The sea surface temperatures are derived from the European Centre for Medium-range Weather Forecasts (ECMWF) re-analysis along the track of CALIPSO. After comparisons with several in situ measurements made by sea buoys during the three campaign days, the accuracy of sea surface temperatures appears to be better than $1 \mathrm{~K}$. This maximum value of $1 \mathrm{~K}$ is thus taken as the associated error.

\subsubsection{Cirrus and liquid clouds}

The forward model takes into account three possible cloud layers: one cirrus layer and two liquid water cloud layers (referred to as mid and low layers hereafter, for being situated in the lower and the middle parts of the troposphere, respectively). The altitude of each layer is determined using the CALIOP data products (Vaughan et al., 2009). Only the cloud layers detected in the 5 -km or 20 -km horizontally averaged resolution of the lidar have been selected. A filter based on the top altitude of each layer has been tested in this study in order to separate the three layers and has proven to be efficient enough to treat the case studies that are analyzed in this paper.

The vertical accuracy of CALIOP at the altitude of cirrus and low liquid water clouds is about $30 \mathrm{~m}$ and $60 \mathrm{~m}$, respectively (Winker et al., 2007). An accuracy of $100 \mathrm{~m}$ is however attributed to the base and the top of each cloud as it corresponds to the minimal size of a sub-layer in our method.

\section{Cirrus clouds}

Our retrieval approach uses ice crystal models developed by Yang et al. (2005) in order to provide the cirrus optical properties that are necessary in the forward model. Seven pristine shapes are considered: Solid Column, Aggregate, Droxtal, Plate, Hollow Column, Bullet Rosette, and Spheroids. Three size distributions are available for each of the seven shapes: one monodisperse distribution (all particles have the same size), and two monomodal gamma generalized size distributions (Walko et al., 1995) describing small and large ice crystals, respectively. These size distributions were precisely tabulated by Dubuisson et al. (2008) for the study of cirrus using IIR measurements. A set of optical properties is thus attributed to a given effective diameter for each combination of shape and size distribution: the extinction coefficient, the asymmetry factor, and the single scattering albedo of the cirrus layer. It should be noted that IIR operational retrievals 
use identical ice crystal shapes, along with a monodisperse size distribution.

The aforementioned study by Dubuisson et al. (2008) has also shown that the IIR measurements have only little sensitivity to the shape and the size distribution of ice crystals, as compared with their sensibility to the size. Therefore no attempt to retrieve these two parameters will be made in this study. In order to ease the analysis of our comparisons with IIR operational products, the crystal shapes used in our retrievals will correspond to the ones retrieved by the operational algorithm of IIR, and the size distribution will be set to monodisperse.

Errors are nevertheless attached to the shape and size distribution used in the retrievals. These parameters being too discontinuous to apply in the standard process of errors calculations described by Eq. (6b), the radiances computed for each crystal shape are compared with the radiances computed for the shape retrieved by IIR, in order to calculate a deviation. For each channel, the error attributed to the crystal shape thus corresponds to the maximal deviation of radiance that is found. A similar process is followed to determine the errors on size distribution.

\section{Liquid clouds}

The microphysical properties of liquid water clouds are simulated using the Lorenz-Mie theory, with an assumed particle size distribution that follows a two-parameter gamma standard distribution. The effective radius of these particles is set to $11 \mu \mathrm{m}$ with an effective variance of 0.13 (Stephens, 1979). A relative error of $10 \%$ is considered for the effective radius.

The 12- $\mu \mathrm{m}$ extinction optical thickness of liquid clouds is calculated from the $532 \mathrm{~nm}$ extinction optical thickness provided by CALIOP (Vaughan et al., 2009). The relative error attached to this parameter is usually also indicated in CALIOP products or is otherwise set to $100 \%$.

\subsubsection{Instrumental accuracy}

The absolute accuracy of IIR is believed to be better than $1 \mathrm{~K}$ (Corlay et al., 2000), whereas CLIMAT-AV absolute accuracy is better than $0.1 \mathrm{~K}$ (Brogniez et al., 2003). Those two maxima are used to characterize the measurement error covariance matrix.

\section{Results}

This section presents the results of an application of our retrieval methodology, based on the three "optimal" days of the CIRCLE-2 and Biscay '08 campaigns outlined in Sect. 2. The retrievals are performed using CLIMAT-AV and IIR data separately, in order to compare the results independently.
For optimal comparisons with IIR operational products, an absorption optical thickness is calculated from the extinction optical thickness values at $12 \mu \mathrm{m}$, using the corresponding single scattering albedo. For this reason, only the absorption optical thickness $\left(\tau_{\mathrm{abs}}\right)$ is discussed in the following results. A detailed analysis of the origins of errors has also been conducted for the case of 16 May 2007, as its results are representative of the two other days. Finally a comparison of our retrievals with IIR operational products has been made in order to strengthen the validity of both methods.

It has to be kept in mind that CLIMAT-AV and IIR measurements were not completely simultaneous and that the two instruments have a different field-of-view. In order to make them more comparable, corrections on the airborne measurements were proposed by Sourdeval et al. (2012), and the same protocol has been followed here. However, that previous study concluded, amongst other things, that despite the corrections, the measurements from both instruments are still not exactly comparable with each other, and a real correlation thus cannot be observed. For this reason, the results of the retrievals obtained from IIR or CLIMAT-AV measurements are only presented globally superimposed.

\subsection{CIRCLE-2: 16 May 2007}

The cloud profile obtained from CALIOP products along the leg of the FF20 aircraft during 16 May 2007 is presented in Fig. 1e. The presence of a large cirrus deck all over the scene with low liquid water clouds underneath is clearly identified. The retrievals of optical thickness and effective diameter along this leg are presented in Fig. 1a, b, respectively. It should be noted that the Fig. 1a-d superimpose results obtained using IIR or CLIMAT-AV measurements (in black and red color, respectively). Figure 1a shows that relatively low optical thicknesses have been retrieved along this leg (between 0 and 0.4 ), with uncertainties of about $10 \%$. Figure $1 \mathrm{~b}$ however shows much larger uncertainties attributed to the retrievals of the effective diameter, which are around $100 \%$ in the first part of the leg (between $47.8^{\circ} \mathrm{N}$ and $48.4^{\circ} \mathrm{N}$ ) and ranging from 30 to $70 \%$ in the second part of the leg, where effective diameters are retrieved with values ranging from 20 to $40 \mu \mathrm{m}$. Global comparisons between the retrievals obtained from IIR or CLIMAT-AV measurements nevertheless show strong similarities for both parameters.

As explained in Sect. 3.2, the cost function $\phi$ can help to analyze the quality of the retrievals. If the cost function is lower than the size of the measurement vector, then the retrieved state vector should allow the forward model to be coherent with the measurements, with respect to their associated errors. The values of the cost function corresponding to the best estimates of the state vector obtained during 16 May 2007 (i.e. the retrievals exposed in Fig. 1a-b) are presented in Fig. 1c. Out of areas where the optical thickness is low (under 0.2), the cost function is well situated under the size of the measurement vector (indicated by a red dashed 

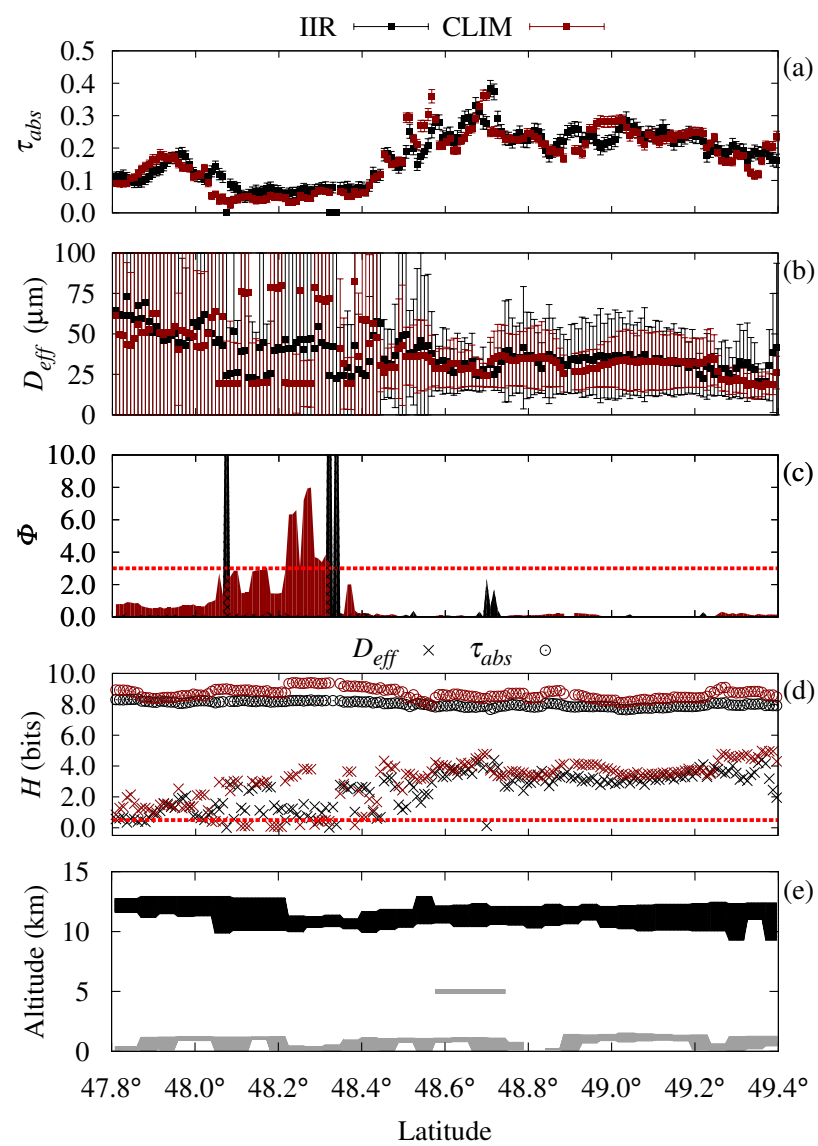

Fig. 1. Results of the retrievals made along the 16 May 2007 leg, using CLIMAT-AV (red) and IIR (black) measurements. (a) Retrieved cirrus absorption optical thickness with error bars. (b) Retrieved effective diameters with error bars. (c) Final values of the cost function. (d) Final information content $H$ in bits (Rodgers, 2000) on each retrieved parameter (crosses for $D_{\text {eff }}$ and circles for $\tau_{\mathrm{abs}}$ ). (e) Cloud profile used in the retrievals (cirrus are plotted in black color and liquid water clouds in grey color).

line), which shows that the retrieved optical thicknesses and effective diameters are at least radiatively equivalent to the reality. Higher values of the cost function appear in the areas where the optical thickness is extremely low, which means that the retrievals may not be reliable. Overall, we can nevertheless expect, judging from Fig. 1c, that the retrieved parameters allow good agreements between the forward model and the measurements. This fact can be verified by comparing directly the measured $(\boldsymbol{y})$ and simulated $(F(\hat{\boldsymbol{x}}))$ radiances. Such comparisons are presented in Fig. $2 \mathrm{a}-\mathrm{f}$ where strong correlations are observed in each channel and for both instruments.

In order to understand these results, a proper information content analysis (as theoretically introduced in the Appendix) has been performed and is presented in Fig. 1d. It is observed that the level of information is high on the optical thickness all over the scene, but is lower on the effective di-
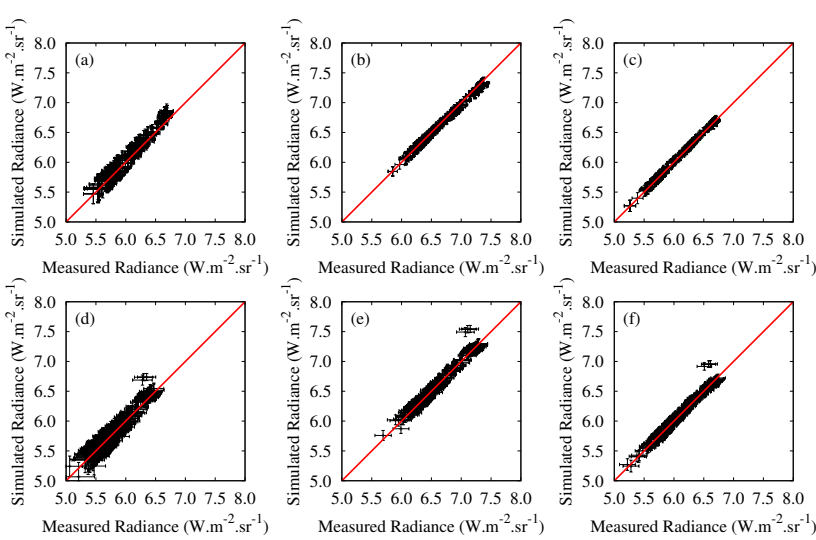

Fig. 2. Scatterplots of comparisons between the radiances measured and the radiances simulated using the optimal retrieved parameters, along the 16 May 2007 leg. (a-c) Using CLIMAT-AV measurements. (d-f) Using IIR measurements. (a, d), (b, e), and (e, f) correspond to the channels centered at $8.65 \mu \mathrm{m}$ (a), $10.60 \mu \mathrm{m}$ (b), and $12.05 \mu \mathrm{m}$, respectively.

ameter, and can even be situated lower than the noise level (represented by a red dotted line) when the cirrus are optically extremely thin. The sensitivity also gets consequently lower when the size of the ice crystals increases, which implies large uncertainties and no information above the noise level for large particles. This behavior can be explained by the fact that cirrus optical properties (e.g. the asymmetry factor, extinction parameter and the single scattering albedo) tend to behave asymptotically toward large particles (over $40 \mu \mathrm{m}$ ) in the infrared region (Yang et al., 2005; Baran et al., 2001). It is nevertheless observed that in areas where the effective diameters are less than $40 \mu \mathrm{m}$ (in the second part of the leg, as aforementioned), the errors are strongly decreasing, and the information content is higher.

For a better understanding of the errors, a detailed analysis of their origins is proposed in this paragraph. This analysis can be done by using the total error covariance matrix $\left(\mathbf{S}_{\epsilon}\right)$ at the end of the iterations. Indeed, this matrix carries the information on the impact that the instrumental accuracy and the errors attached to non-retrieved parameters have in each channel. The black lines in Fig. 3a-c represent the relative errors in each measurement channel due to the accuracy of the instruments and of the non-retrieved parameters, i.e. the ratio between $\sigma_{\epsilon_{\lambda}}$ (that is, the square root of a diagonal component of $\mathbf{S}_{\epsilon}$ ), and $F_{\lambda}(\hat{\boldsymbol{x}})$. Under these lines, the contributions of each group of non-retrieved parameter (cf. Sect. 3.3) and of the instrumental accuracy to the relative errors are represented. From these figures, it can first be observed that the relative errors in channel $\mathrm{C} 08$ are much higher than in the other channels. This is primarily due to the insufficient knowledge of cirrus non-retrieved parameters (in grey), such as the ice crystal shape that strongly impacts this channel. An impact of liquid water clouds (in pink and dark-blue) can 

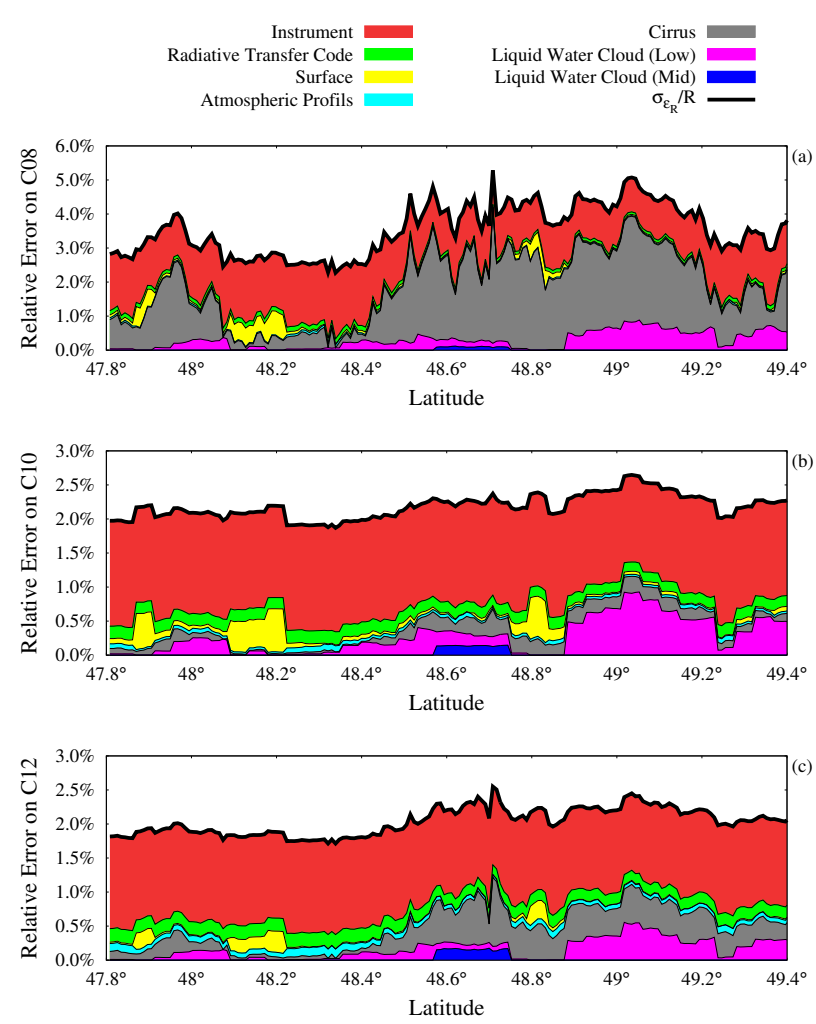

Fig. 3. Total relative errors (thick plain black line) associated to each measurement vector components corresponding to the $8.65 \mu \mathrm{m}$ (a), $10.60 \mu \mathrm{m}$ (b), and $12.05 \mu \mathrm{m}$ (c) channels of IIR, with the decomposition of their origins (in color patterns).

also be observed in each channel. This impact increases with their altitudes, as the gradient of temperature with the ground gets higher. In channels $\mathrm{C} 10$ and $\mathrm{C} 12$, the errors are dominated by measurements, which is the expected situation in a good optimal estimation scheme. Indeed, if a non-retrieved parameter brings more uncertainties than the measurement itself, this means that it should also be part of the state vector. This kind of error analysis study is thus extremely valuable for identifying what additional parameters could be retrieved with the same amount of information. For instance, a proper retrieval of the crystal shape would be difficult with this methodology since this parameter is very discretized. Indirect attempts have been made in this study, by testing which ice crystal shape reduces the cost function the most, but results have not been successful enough since the cost function is already very low. The ice particle shape provided by IIR is thus trusted. It should however be noted that, despite the fact that correlations between the measurements have been neglected in our study, these correlations may still exist and consequently limit the amount of pieces of information to be retrieved. The accurate retrieval of an additional parameter could therefore necessitate the addition of new independent measurements to the measurement vector.
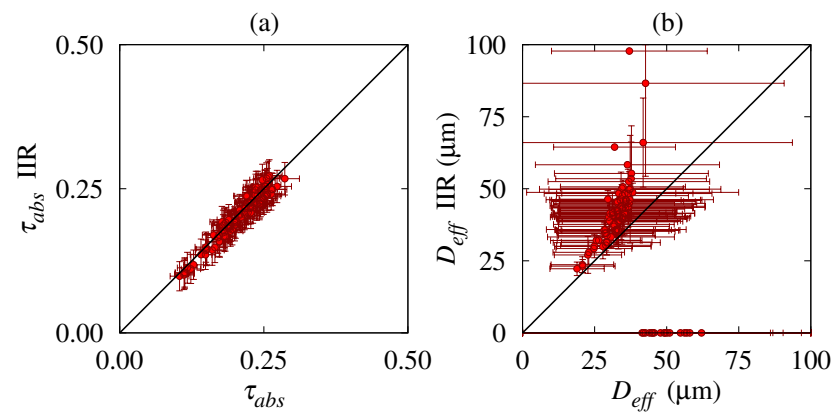

Fig. 4. Scatterplots of our retrievals results versus IIR operational products, compared pixel per pixel along the 16 May 2007 leg. (a) The absorption optical thicknesses with their uncertainties. (b) The effective diameters with their uncertainties. Only operational retrievals obtained with an upper layer composed exclusively of high ST layers are presented.

Finally, our retrievals have been compared pixel per pixel with IIR operational retrievals of effective absorption optical depth at $12.05 \mu \mathrm{m}$ (Garnier et al., 2012) and ice crystal effective diameter, as presented in Fig. 4a, b, respectively. It should be reminded that identical atmospheric profiles and ice crystal models have been used in both retrieval methods. Such comparisons aim to strengthen the validity of both methods since they adopt different approach for the retrieval of ice cloud properties. However these comparisons still need to be carefully considered due to possible differences between the cloud profiles used in both methods. Indeed, despite the use of identical information (from CALIOP products) for identifying cloud layers, the different treatment of these layers by both methods can lead to strong divergences between their retrievals. The IIR operational algorithm first determines a background reference, which can be either the surface or the highest opaque layer detected by CALIOP (hereafter referred to as the lower layer). Each semi-transparent (ST) layer detected above the reference is later used to compose a unique cloud layer called the upper layer, which properties will be retrieved. The ST layers are characterized by centroid parameters (i.e. altitude or temperature) provided by CALIOP products (Vaughan et al., 2005b). Hereafter, each ST layer composing the upper layer will be referred to as high or low depending if their centroid altitude is situated higher or lower than $7 \mathrm{~km}$, respectively. The centroid parameters of the upper layer correspond to the mean of the centroid parameters of each ST clouds above the reference, weighted by their respective mean attenuated scattering backscatter. The centroid altitude of the upper layer must be higher than $7 \mathrm{~km}$, although high and low ST clouds may be used in its composition depending on the IIR classification type (Garnier et al., 2012). The presence of low ST cloud layers can however be the cause of strong divergences with our methodology, as we only consider layers with a top altitude higher than $7 \mathrm{~km}$ to compose our cirrus. 

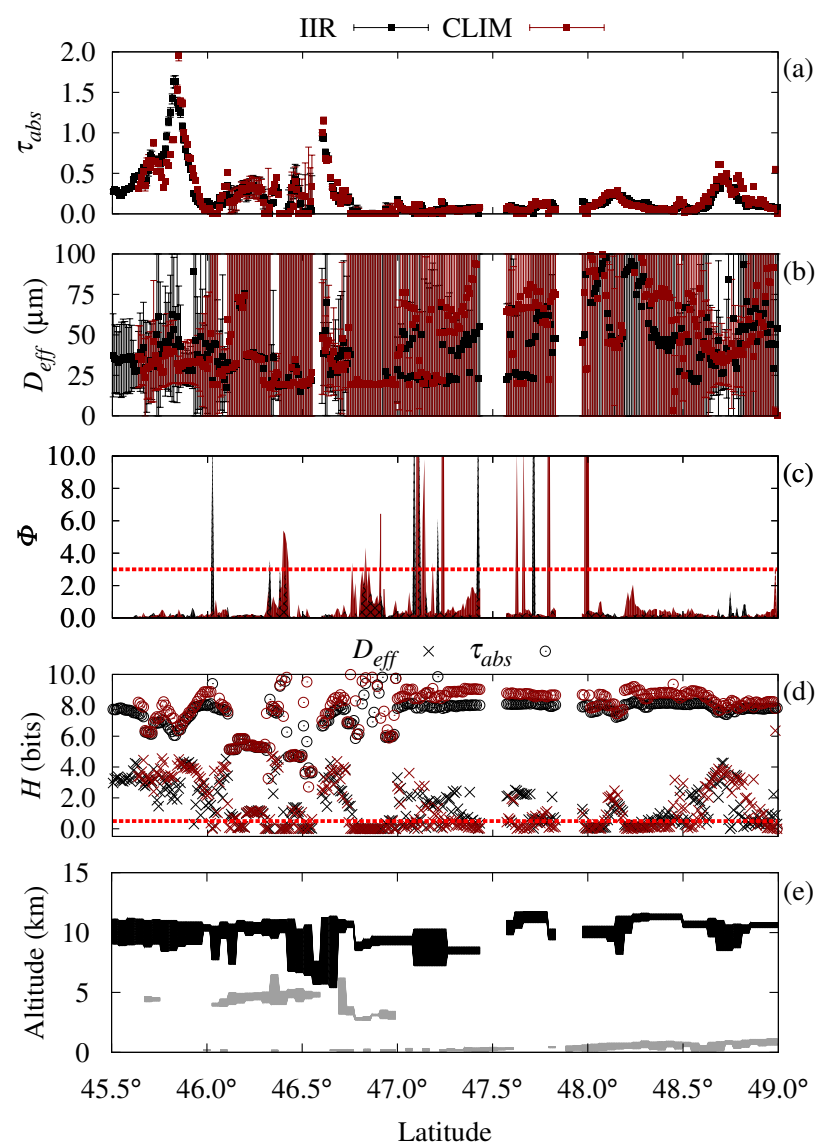

Fig. 5. Similar to Fig. 1, for 25 May 2007.

It thus appears that comparisons between our retrievals and IIR operational products are meaningful when the IIR upper layer is composed only of high ST clouds (IIR classification type 21,31 or 40 ). Under this condition, the optical thickness and effective diameter would be retrieved for clouds with absolutely similar top and base altitude in both methods. Only retrievals obtained in such conditions are consequently shown in Fig. 4a-b.

Fig. 4a shows a strong correlation between the retrieved absorption optical thicknesses. A slight deviation appears in the retrievals of effective diameters presented in Fig. 4b, but the differences remain acceptable after taking the uncertainties assigned to the retrievals into account. It can also be noticed that the uncertainties attached to the effective diameters are significantly higher in our method than in IIR operational retrievals, but further comparisons need to be done. Overall, it can nevertheless be concluded that good correlations with IIR products are found, for both retrieved parameters, when the cirrus layers have similar locations. (a)

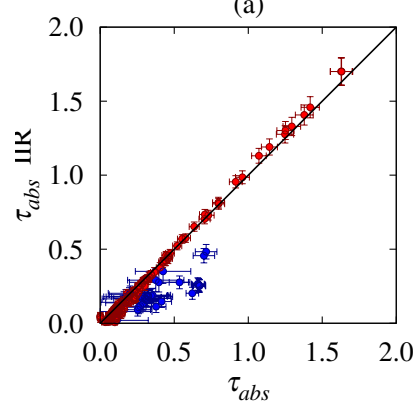

Fig. 6. Similar to Fig. 4, for 25 May 2007. A blue color indicates retrievals corresponding to pixels where a mid liquid water cloud was present in the cloud profile treated by our methodology.

\subsection{CIRCLE-2: 25 May 2007}

The cloud profile obtained for 25 May 2007 is presented in Fig. 5e. This figure shows the presence of scattered cirrus all over the scene with liquid water clouds in the middle part of the troposphere underneath between $46.2^{\circ} \mathrm{N}$ and $47.0^{\circ} \mathrm{N}$. Low liquid water clouds are present on the rest of the leg.

The retrievals effectuated along this leg are presented in Fig. 5a, b. Figure 5a shows that the optical thicknesses are accurately retrieved, yet with larger uncertainties in the presence of mid liquid water clouds. Figure $5 \mathrm{~b}$ however shows that apart from few areas (i.e. between $45.5^{\circ} \mathrm{N}$ and $46.0^{\circ} \mathrm{N}$ or around $46.6^{\circ} \mathrm{N}$ and $47.65^{\circ} \mathrm{N}$ ), high uncertainties (around $100 \%$ ) are attributed to the retrievals of the effective diameter. This can be explained by the fact that, similarly to the case of 16 May 2007, the optical thickness is very low (lesser then 0.2 ) along almost the whole track. The aforementioned specific areas where the retrievals of effective diameters are more accurate indeed seem correlated with an increase of the optical thickness. The presence of large crystals also contributes to higher uncertainties since the measurements carry less information. Despite this lack of confidence in the retrievals of the effective size, the values of the cost functions presented in Fig. 5c show a globally good confidence in retrievals during this campaign day. Strong global agreements between the retrievals obtained from IIR and CLIMAT-AV measurements are also observable for both parameters.

The information content analysis presented in Fig. 5d shows that the information on the effective diameter is mostly situated under the noise level when the optical thickness is low, which is perfectly coherent with the previous observations. The presence of liquid water clouds all along the leg, especially when situated in the mid-troposphere, also deteriorates the information on cirrus properties carried by the measurement, and therefore adds to the difficulties in retrieving an accurate effective diameter.

Direct comparisons with IIR operational products have also been performed for this campaign day and show good coherence between the retrievals of both methodologies, as 

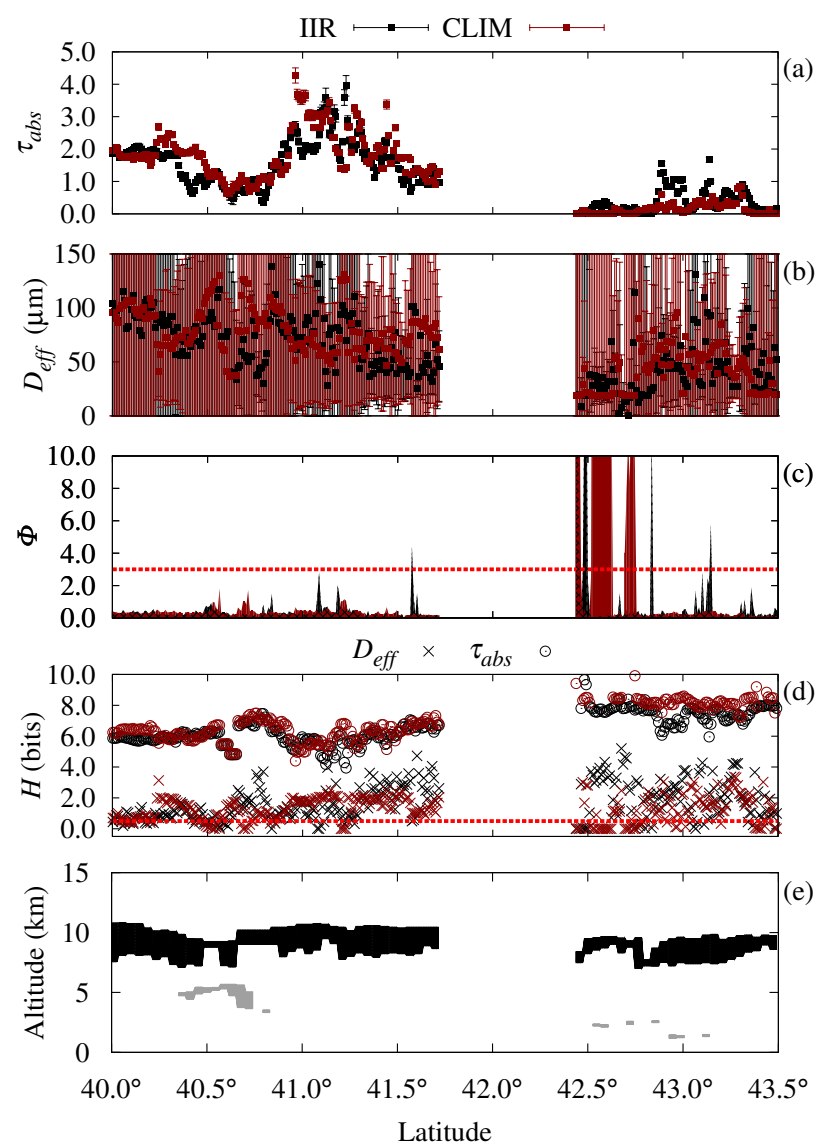

Fig. 7. Similar to Fig. 1, for 18 October 2008.

observed in Fig. 6a, b for the absorption optical thickness and the effective diameter, respectively. Like in the previous case study, the red dots correspond to retrievals obtained in pixels where the position of the cirrus layers are similar between both methods. The additional blue color indicates the presence of a mid liquid water cloud layer in the cloud profile used by our methodology. Since these clouds are often considered opaque in the operational algorithm, the background temperature used to compute the effective emissivity does not correspond to the surface temperature, but to the temperature of the atmosphere at cloud top. In the case of mid liquid water clouds that are not perfectly opaque to infrared measurements, the impact of the surface might be mistakenly neglected, and the background temperature might be lower than it should be. The radiative impact of cirrus would thus be underestimated, which would result in the retrieval of a lower optical thickness by IIR operational method. Out of those specific areas, a strong correlation can be observed between both retrieved optical thicknesses (red dots). Such conclusion would be hard to make concerning the effective diameter, due to the high uncertainties attributed to its values by each retrieval method. Figure $6 \mathrm{~b}$ shows that the effective diameters are again much less correlated than the optical
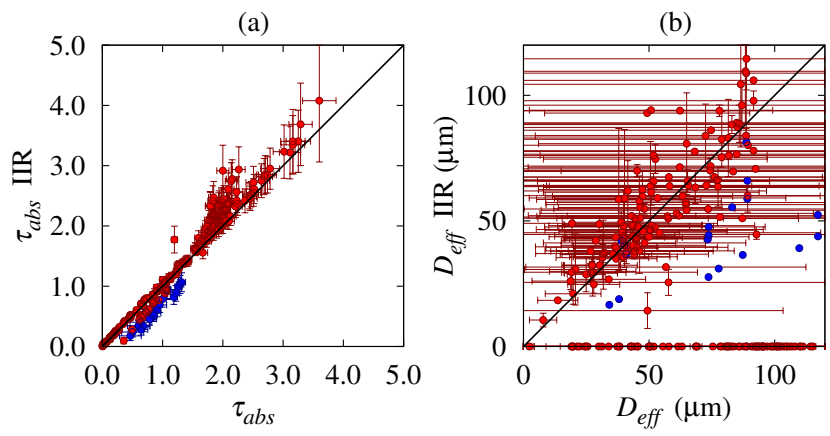

Fig. 8. Similar to Fig. 6, for 18 October 2008.

thicknesses. Comparisons between IIR operational products and our retrievals of the effective diameter are nevertheless satisfactory when taking into account their respective uncertainties.

\subsection{CALIPSO-BISCAY: 18 October 2008}

During the 18 October 2008, CALIOP products (presented in Fig. 7e) show two extended cirrus decks with only few liquid water clouds underneath.

The retrievals of optical thickness and effective diameter obtained along this leg are presented in Fig. 7a, b, respectively. High values of optical thickness are found between 40.0 and $41.6^{\circ} \mathrm{N}$, with good agreements between the two instruments. The retrievals of effective diameters are nevertheless inaccurate along almost all the track, possibly due to their high values (over $50 \mu \mathrm{m}$ ) during this campaign day, which implies low information carried by the infrared channels. The information content analysis presented in Fig. 7d supports this conclusion by indicating a lack of information on the effective diameters along most of the scene. Despite this lack of information on the effective size, the values of the cost function presented in Fig. 7c show that the retrievals allow the forward model to be coherent with the measurements.

The comparisons with IIR operational retrievals presented in Fig. 8a, b show strong similarities. These results are coherent with the observations made for the previous campaign days. A slight deviation can be observed for large optical thicknesses, but larger uncertainties and possible contribution from multiple scattering in the IIR retrievals (up to 5-10\%) make them acceptable. The comparisons between the two methods are again satisfactory.

\section{Comparisons with CIRCLE-2 in situ measurements}

The microphysical and optical in situ observations discussed in this section were performed onboard the GF20 aircraft that flew inside cirrus decks right under the track of the FF20 aircraft. The altitude of the GF20 during two selected scenes of 16 May and 25 May 2007 is exposed in Fig. 9a, 


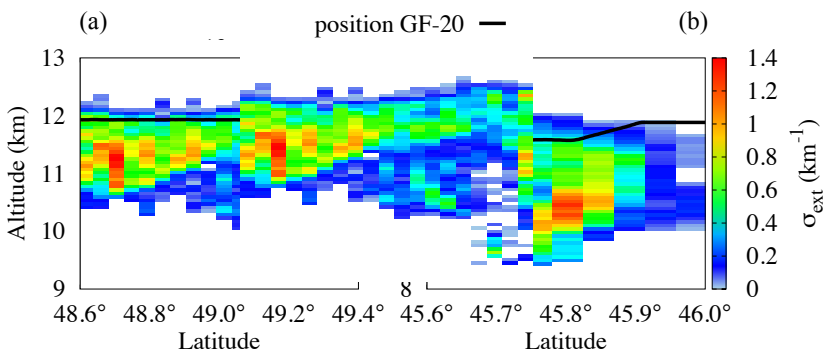

Fig. 9. Altitude of the GF20 aircraft during selected legs of 16 May 2007 (a) and 25 May 2007 (b). The extinction profiles correspond to CALIOP products at $1 \mathrm{~km}$ horizontal resolution.

$\mathrm{b}$, respectively. In these figures, the cloud positions and extinction profiles are provided by CALIOP products (Vaughan et al., 2009). It should be noted that these extinction profiles are purely informative and will not be compared to CIRCLE2 measurements since such a study has already been successfully performed by Mioche et al. (2010). The instruments used in this study for the assessment of in situ effective diameters and extinction coefficients included three independent techniques: the Polar Nephelometer (PN), the SPEC Incorporated Cloud Particle Imager (CPI), and the PMS Forward Scattering Spectrometer Probe 300 (FSSP-300). The combination of these techniques provides a description of cloud particles within a size range varying from a few micrometers (typically $3 \mu \mathrm{m}$ for the PN and the FSSP-300) to about $2 \mathrm{~mm}$ (for the CPI). The method of data processing, the reliability of the instruments and the uncertainties of the derived microphysical and optical parameters are described in detail by Gayet et al. (2006).

The Polar Nephelometer (Gayet et al., 1997) measures the angular scattering pattern (non normalized scattering phase function) of an ensemble of cloud particles (i.e., water droplets, ice crystals, or a mixture of these particles) ranging from a few micrometers to approximately $1 \mathrm{~mm}$ in diameter. The measurements are performed at a wavelength of $0.8 \mu \mathrm{m}$ with scattering angles ranging from $\pm 15^{\circ}$ to $\pm 162^{\circ}$ and with a resolution of $3.5^{\circ}$. In this study, direct measurements of the scattering phase function are used to calculate the extinction coefficient with an uncertainty estimated to be $25 \%$ (Gayet et al., 2002).

The CPI registers cloud particle images on a solid state, one-million-pixel digital charge-coupled device (CCD) camera by freezing the motion of the particle using a 40-ns pulsed, high power laser diode (Lawson et al., 2001). Each pixel in the CDD camera array has an equivalent size in the sample area of $2.3 \mu \mathrm{m}$, so particles of sizes from approximately $20 \mu \mathrm{m}$ to $2 \mathrm{~mm}$ are imaged. The method of data and image processing as well as the calibration of the CPI are described in detail by Gayet et al. (2009). In the present study, the CPI measurements are mainly used to derive the ice water content (IWC) of particles with size larger than approximately $20 \mu \mathrm{m}$. The IWC is determined following the method proposed by Lawson and Baker (2006) with an uncertainty expected to be around $60 \%$.

The FSSP-300 instrument provides information on the particle size distribution for the size range $3 \mu \mathrm{m}-21.8 \mu \mathrm{m}$ (Baumgardner et al., 1992). The upper size limit $(21.8 \mu \mathrm{m})$ of the instrument was selected in order to be consistent with the first channel of the CPI in terms of particle concentration and ice water content. For the calculation of the ice water content, the particles are assumed to be ice crystals with a density of $0.9 \mathrm{~g} \mathrm{~cm}^{-3}$. The accuracy of the IWC measurements is estimated to be around $75 \%$ (Gayet et al., 2002).

In this section, the comparison between the cloud properties retrieved from CLIMAT-AV remote sensing observations and obtained from in situ observations will focus on the visible extinction coefficient and the effective diameter. The visible extinction $\left(\sigma_{\text {ext }}\right)$ is derived from the PN measurements. Mioche et al. (2010) showed that the PN extinction coefficient is more accurate and is well correlated with the extinction derived from the combination of the FSSP-300 and CPI measurements. The effective diameter $\left(D_{\text {eff }}\right)$ is calculated using the following relationship:

$D_{\text {eff }}=A \frac{\text { IWC }}{\sigma_{\text {ext }}}$,

with $D_{\text {eff }}$ expressed in $\mu \mathrm{m}$, IWC in $\mathrm{g} \mathrm{m}^{-3}, \sigma_{\text {ext }}$ in $\mathrm{km}^{-1}$, and $A=3000 \mathrm{~mm}^{3} \mathrm{~g}^{-1}$ (Gayet et al., 2006). In this relationship, IWC is the combined ice water content calculated from the FSSP-300 and CPI measurements; $\sigma_{\text {ext }}$ is obtained from the PN measurements. Therefore, the accuracy of the effective diameter is estimated to be within 55-65\%. However, the accuracies of the derived microphysical parameter could be seriously reduced by the shattering of large ice crystals on the probes inlets (see McFarquhar et al., 2007, Korolev and Isaac, 2005, and Heymsfield, 2007 for further details).

The in situ measurements have been averaged over $5 \mathrm{~s}$ (i.e $1 \mathrm{~km}$ according to the mean Falcon-20 airspeed) in order to be consistent with the IIR and CLIMAT-AV products presented in the previous section and to reduce the inherent errors in comparing two different aircraft measurements. Figure $10 \mathrm{a}, \mathrm{b}$ shows the comparison between in situ measurements (in red) and CLIMAT-AV retrievals (in black) for a collocated leg during 16 May 2007. The visible extinction corresponding to CLIMAT-AV retrievals have been directly obtained from the extinction optical thickness $(\tau)$ retrieved by our methodology.

The crystal shape used for CLIMAT-AV retrievals during 16 May 2007 has been set to plate in order to be coherent with the dominant crystal habits observed by the CPI along this leg (Mioche et al., 2010). Comparisons between the products obtained from in situ observations and our methodology show strong agreements for the effective diameter and the visible extinction. The retrieved and in situ estimated effective diameters have the same order of magnitude all over the leg, yet the latter having lower values. This observation can be explained by the shattering effects on probes inlets, 

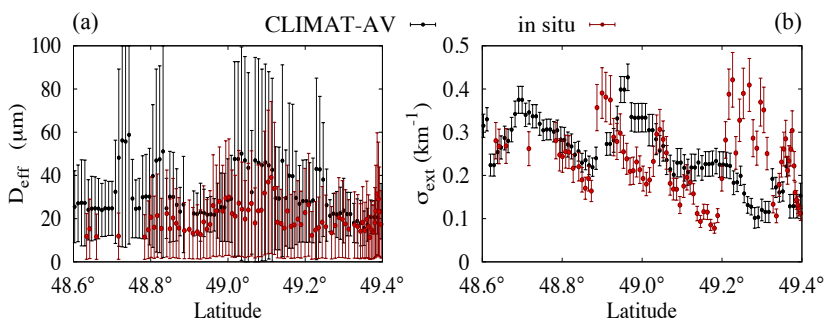

Fig. 10. Effective diameter (a) and visible coefficient (b) retrieved from the GF20 instruments (in red) and by our methodology using CLIMAT-AV measurements (in black) for the 16 May 2007 leg presented in Fig. 9a.

but also by the fact that the GF20 performs measurements at the top of the cirrus deck (see Fig. 9a), whereas CLIMAT$\mathrm{AV}$ measurements are, due to the low optical thickness of the cloud, more sensitive to integrated cirrus properties. It should therefore be expected that retrievals from radiometric estimates indicate higher vertically averaged values of effective diameter than in situ estimates obtained at cirrus top. Considering that the in situ estimates could be biased to lower values by the aforementioned effects, our retrieval and in situ estimates are consistent for the effective radius, and well within uncertainties. A similar effect can also explain the differences observed for the visible extinction, as the CLIMAT-AV extinctions are extracted from the cloud optical thicknesses (i.e. vertically integrated), whereas the in situ extinction is representative of the cloud top. Large differences are noticeable between $49.2^{\circ}$ and $49.4^{\circ} \mathrm{N}$, but they can be explained by a possible area of higher extinction within the cirrus as this latitude range corresponds to measurements performed at a lower altitude in the cirrus (see Fig. 9a). Despite the difficulties in comparing in situ and remote sensing measurements, the orders of magnitude are well respected.

Figure $11 \mathrm{a}, \mathrm{b}$ presents a similar study effectuated for 25 May 2007. The CPI observations indicated a dominant mixture of plate and bullet rosette during this leg (Mioche et al., 2010), and the ice crystal shape has thus been set to plate as our retrieval approach only allows to use one kind of pristine shape. As observed for the case of 16 May 2007, the in situ measurements indicate smaller values of effective diameter and extinction than the retrievals obtained from CLIMAT-AV measurements, which can be explained by the aforementioned expected differences between in situ and remote sensing products. The discrepancy observed between $45.85^{\circ}$ and $46.0^{\circ} \mathrm{N}$ is explained by the fact that the GF20 slowly exited the cirrus deck in this latitude range (see Fig. 9b). These comparisons nevertheless allow concluding that the retrievals obtained from CLMAT-AV measurements and the in situ observations are well within uncertainties.
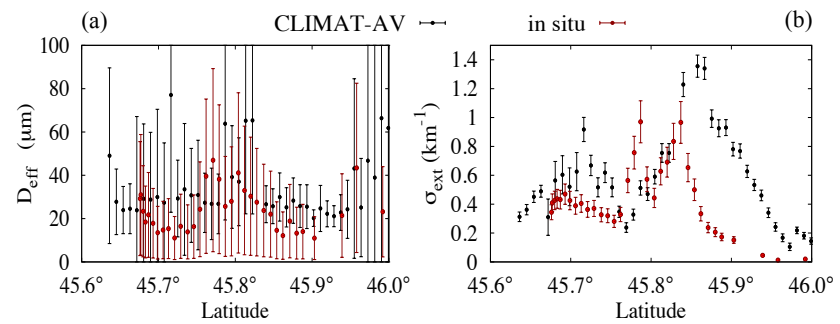

Fig. 11. Effective diameter (a) and visible coefficient (b) retrieved from the GF20 instruments (in red) and by our methodology using CLIMAT-AV measurements (in black) for the 25 May 2007 leg presented in Fig. 9b.

\section{Summary/conclusion}

This study presents a novel methodology that uses the information contained in three thermal infrared channels to retrieve the optical thicknesses and effective diameters of ice crystals of cirrus. The approach is based on a variational method, which uses a Levenberg-Marquardt minimization scheme to find the best estimate of the parameters to be retrieved. This method has the advantage of clearly transcribing the uncertainties due to each non-retrieved parameter and instrumental accuracy on the retrieval, and allows the combined use of the information content theory.

Three days of the validation campaigns CIRCLE-2 and Biscay ' 08 have been used as case studies to perform the retrievals. The infrared measurements are provided by the IIR radiometer onboard CALIPSO and by the collocated airborne radiometer CLIMAT-AV. The cirrus optical thicknesses are found to be accurately retrieved during the three campaign days whereas larger uncertainties appear on the retrieved effective diameters. An information content analysis has been performed and clearly showed a lack of information on the particle effective size, with a level of information that is often less than the noise level when the particles are too large or when the cirrus is optically extremely thin. Information on the optical thickness is always sufficient for accurate retrievals, but tends to become lower for high optical thicknesses or in the presence of liquid clouds in the mid-troposphere. Nevertheless analyses of the cost function have shown good global confidence in the retrievals during the three days and prove that the retrieved parameters allows the forward model to be consistent with the measurements (with respect to the attached uncertainties).

Comparisons between retrievals independently obtained using IIR or CLIMAT-AV measurements are consistent with the results of a previous validation study by Sourdeval et al. (2012) that pointed out difficulties in comparing radiometric data over cirrus decks without an accurate knowledge of their properties. We have shown in this study that strong similarities are found between the optical thicknesses retrieved using the respective measurements of both radiometers. Such conclusion would be harder to make concerning the effective 
diameters because of the large uncertainties attached to this parameter, but the comparisons are still satisfactory, particularly during the leg of 16 May 2007, where uncertainties are lower.

The retrievals made during this study have also been compared with IIR operational products. Similar atmospheric profiles and ice crystal models have been used in order to make the retrievals perfectly comparable. In the case of similar cloud positioning between both methods (i.e. when the upper layer of IIR algorithm is only composed of high semitransparent layers), the retrievals of optical thicknesses appear to be well correlated. The correlations between effective diameters are, again, more difficult to observe due to large uncertainties. Comparisons of the exact retrieved values (without the attached uncertainties) nevertheless show good correlations. These comparisons thus strengthen the validity of both methods since different retrievals approaches are used. The uncertainties attributed to effective diameters are nevertheless found be significantly lower in IIR products. Our retrievals have also shown to be globally consistent with the in situ estimates obtained during CIRCLE-2. Higher values of effective diameters and visible extinctions are found by our methodology, but these differences can be explain by inherent difficulties in comparing remote sensing products with in situ estimations (i.e. the shattering of ice crystals and/or the specific altitude of the plane in the cirrus decks).

Finally, an error analysis has been led in order to determine which non-retrieved parameters have the strongest impact on the forward model errors. It appears that the impact of uncertainties related to the choice of the ice crystal shape is consequent on the 8.6- $\mu \mathrm{m}$ channel of IIR. Also, the presence of liquid clouds is responsible for large uncertainties in the three channels. This error analysis, together with the information content analyses, helps to understand how the quality of the retrievals could be improved for future studies. On one hand, the information content analyses show that there is a lack of information on the cirrus particle effective diameters. On the other hand, the error analyses show that the shape of ice crystals as well as the radiative and microphysical properties of liquid water clouds underneath have a strong impact on the forward model uncertainties. Therefore, to significantly improve the retrievals, those parameters (i.e. liquid cloud effective radius, optical depth, and ice crystals shape) should be added to the state vector. Information on these 'new' parameters could be provided by additional measurements in the visible and near infrared regions (with the possible help of polarization). The choice of more realistic ice crystal models (i.e. representative of shape mixtures) could also help reducing the uncertainties.

\section{Appendix A}

\section{The information content theory as applied to optimal estimation}

If the remote sensing literature is full of algorithm descriptions for inferring atmosphere parameters from distinct combination of measurements (Miller et al., 2000), very little reference is made to the information content carried out by such combinations. Worden et al. (1999) and Evans et al. (2002), for instance, theoretically studied how much information content is gained in a retrieval, relatively to the prior knowledge of the system or the amount of information provided by additional measurements. More recently, L'Ecuyer et al. (2006) and Cooper et al. (2006) developed a detailed information content analysis in order to select an optimal combination of visible, near-infrared and thermal infrared channels for liquid and ice clouds properties retrievals.

In the present study a similar information content analysis is made, focused on IIR measurements. The aim is nevertheless not to find the best channel combinations but to understand the limits of the observing system to retrieve the selected ice cloud properties. A detailed information content analysis is thus not performed but is just used to emphasize some conclusions in the retrievals.

Rodgers (2000) uses channel information content to relate directly entropy to a state described by its probability density function, as mentioned previously. In the case of a Gaussian probability density function Rodgers has demonstrated that the entropy ascribed to a vector $\boldsymbol{x}$ can be written as

$S[P(x)]=\frac{1}{2} \log _{2}\left|\mathbf{S}_{x}\right|+c$,

where $P(x)$ is the probability density function attached to $\boldsymbol{x}$ and $c$ is a constant. From Eq. (A1) it is possible to define the information content $H$ (in bits) in the state space as the difference of entropy between the prior knowledge of the system (i.e. $S[P(\boldsymbol{x})]$, before the measurement is made) and the posterior knowledge of the system (i.e. $S[P(\boldsymbol{x} \mid \boldsymbol{y})]$, after the measurement is made). The entropy $H$ is thus calculated as presented in the following relationship:

$$
\begin{aligned}
H & =S[P(\boldsymbol{x})]-S[P(\boldsymbol{x} \mid \boldsymbol{y})] \\
& =\frac{1}{2} \log _{2}\left|\mathbf{S}_{a}\right|-\frac{1}{2} \log _{2}\left|\mathbf{S}_{x}\right| \\
& =\frac{1}{2} \log _{2}\left|\mathbf{S}_{x}^{-1} \mathbf{S}_{a}\right|,
\end{aligned}
$$

where $\boldsymbol{x}$ and $\boldsymbol{y}$ represent the state and measurement vectors, respectively. With the entropy defined as the logarithm in base 2 of the total number of states, $H$ provides the information content in bits, which implies theoretically that the measurements allow to distinguish between $2^{H}$ states within the prior state space. 
By using Eqs. (10) and (A2), $H$ can be presented as

$H=\frac{1}{2} \log _{2}\left|\tilde{\mathbf{K}}^{T} \tilde{\mathbf{K}}+\mathbf{I}_{n}\right|$

where $\tilde{\mathbf{K}}$ is a modified kernel matrix, defined by

$\tilde{\mathbf{K}}=\mathbf{S}_{\epsilon}{ }^{-\frac{1}{2}} \mathbf{K} \mathbf{S}_{a}^{\frac{1}{2}}$.

It has previously been seen that $\mathbf{K}$ contains information on the sensitivity to the measurement. This matrix appears to be difficult to interpret but Rodgers (2000) shows that the $\tilde{\mathbf{K}}$ matrix is perfectly representative of the signal to noise ratio. When the singular values of $\tilde{\mathbf{K}}$ are greater than unity, thus when $H$ greater than 0.5 (cf. Eq. A3a), it can be considered that the measurements bring information on the parameters to be retrieved. Consequently, parameters retrieved with $H$ that tends toward 0.5 will be expected to be very inaccurately retrieved. If the entropy is lower than 0.5 then the measurements do not add any information to the a priori knowledge.

Acknowledgements. This work was funded by the Centre National d'Études Spatiales (CNES). We thank the member of Deutsches Zentrum für Luft- und Raumfahrt (DLR) and Service des Avions Français Instrumentés pour la Recherche en Environnement (SAFIRE) who organized the aircraft operations and experiment management. We would like to acknowledge ICARE center (http://www.icare.univ-lille1.fr) in Lille, France, for the A-Train data.

Edited by: O. Dubovik

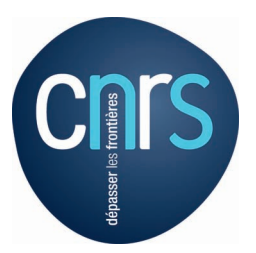

The publication of this article is financed by CNRS-INSU.

\section{References}

Ackerman, S. A., Smith, W. L., Revercomb, H. E., and Spinhirne, J. D.: The 27-28 October 1986 FIRE IFO cirrus case study: spectral properties of cirrus clouds in the $8-12 \mu \mathrm{m}$ window, Mon. Weather Rev., 118, 2377-2388, 1990.

Baran, A. J.: A review of the light scattering properties of cirrus, J. Quant. Spectrosc. Ra., 110, 1239-1260, 2009.

Baran, A. J., Yang, P., and Havemann, S.: Calculation of the single-scattering properties of randomly oriented hexagonal ice columns: A comparison of the t-matrix and the finite-difference time-domain methods, Appl. Optics, 40, 4376-4386, 2001.

Baran, A. J., Connolly, P. J., and Lee, C.: Testing an ensemble model of cirrus ice crystals using midlatitude in situ estimates of ice water content, volume extinction coefficient and the total solar optical depth, Q. J. Roy. Meteor. Soc., 110, 1579-1598, 2009.

B. A. Baum, P. Yang, A. J. Heymsfield, C. G. Schmitt, Y. Xie, A. Bansemer, Y.-X. Hu, and Z. Zhang. Improvements in shortwave bulk scattering and absorption models for the remote sensing of ice clouds, J. Appl. Meteor. Clim., 50, 1037-1056, 2011.
Baumgardner, D., Dye, J. E., Gandrud, B. W., and Knollenberg, R. G.: Interpretation of measurements made by the forward scattering spectrometer probe (FSSP-300) during the airborne arctic stratospheric expedition, J. Geophys. Res., 97, 8035-8046, 1992.

Brogniez, G., Pietras, C., Legrand, M., Dubuisson, P., and Haeffelin, M.: A high-accuracy multiwavelength radiometer for in situ measurements in the thermal infrared, Part 2: Behavior in field experiments, J. Atmos. Ocean. Tech., 20, 1023-1033, 2003.

Brogniez, G., Parol, F., Becu, L., Jourdan, O., Gayet, J.-F., Auriol, F., Verwaerde, C., Balois, J.-Y., and Damiri, B.: Determination of cirrus radiative parameters from combination between active and passive remote sensing measurements during FRENCH/DIRAC 2001, Atmos. Res., 72, 425-452, 2004.

Cooper, S. J., L'Ecuyer, T. S., and Stephens, G. L.: The impact of explicit cloud boundary information on ice cloud microphysical property retrievals from infrared radiances, J. Geophys. Res., 108, 4107, doi:10.1029/2002JD002611, 2003.

Cooper, S. J., L'Ecuyer, T. S., and Gabriel, P.: Objective assessment of the information content of visible and infrared radiance measurements for cloud microphysical property retrievals over the global oceans, Part 2: Ice clouds, J. Appl. Meteorol., 45, 42-62, 2006.

Cooper, S. J., L'Ecuyer, T. S., Gabriel, P., and Baran, A. J.: Performance assessment of a five-channel estimation-based ice cloud retrieval scheme for use over the global oceans, J. Geophys. Res., 112, D04207, doi:10.1029/2006JD007122, 2007.

Corlay, G., Arnolfo, M.-C., Bret-Dibat, T., Lifferman, A., and Pelon, J.: The infrared imaging radiometer for PICASSO-CENA, Tech. rep., CNES, 2000.

Delanoë, J. and Hogan, R. J.: Combined CloudSat-CALIPSOMODIS retrievals of the properties of ice clouds, J. Geophys. Res, 115, D00H29, doi:10.1029/2009JD012346, 2010.

Dubuisson, P., Buriez, J. C., and Fouquart, Y.: High spectral resolution solar radiative transfer in absorbing and scattering media: application to the satellite simulation, J. Quant. Spectrosc. Ra., 55, 103-126, 1996.

Dubuisson, P., Giraud, V., Chomette, O., Chepfer, H., and Pelon, J.: Fast radiative transfer modeling for infrared imaging radiometry, J. Quant. Spectrosc. Ra., 95, 201-220, 2005.

Dubuisson, P., Giraud, V., Pelon, J., Cadet, B., and Yang, P.: Sensitivity of thermal infrared radiation at the top of the atmosphere and the surface to ice cloud microphysics, J. Appl. Meteorol. Clim., 47, 2545-2560, doi:10.1175/2008JAMC1805.1, 2008.

Evans, K. F., Walter, S. J., Heymsfield, A. J., and McFarquhar, G. M.: Submillimeter-wave cloud ice radiometer: simulations of retrieval algorithm performance, J. Geophys. Res., 107, 4028, doi:10.1029/2001JD000709, 2002.

Fletcher, R.: A modified Marquardt subroutine for nonlinear least squares, Tech. Rep. R6799, Atomic Energy Research Establishment, 1971.

Forster, P., Ramaswamy, V., Artaxo, P., Berntsen, T., Betts, R., Fahey, D., Haywood, J., Lean, J., Lowe, D., Myhre, G., Nganga, J., Prinn, R., Raga, G., Schulz, M., and Dorland, R. V.: Changes in atmospheric constituents and in radiative forcing, in: Climate Change 2007: the Physical Science Basis, Contribution of Working Group I to the Fourth Assessment Report of the Intergovernmental Panel on Climate Change, edited by: Solomon, S., Qin, D., Manning, M., Chen, Z., Marquis, M., Averyt, K., Tig- 
nor, M., and Miller, H., Cambridge University Press, Cambridge, UK and New York, NY, USA, 2007.

Fusina, F., Spichtinger, P., and Lohmann, U.: Impact of ice supersaturated regions and thin cirrus on radiation in the midlatitudes, J. Geophys. Res.-Atmos., 112, D24S14, doi:10.1029/2007JD008449, 2007.

Garnier, A., Pelon, J., Dubuisson, P., Faivre, M., Chomette, O., Pascal, N., and Kratz, D. P.: Retrieval of cloud properties using CALIPSO imaging infrared radiometer, Part 1: effective emissivity and optical depth, J. Appl. Meteorol. Clim., 51, 1407-1425, doi:10.1175/JAMC-D-11-0220.1, 2012.

Gayet, J. F., Crépel, O., Fournol, J. F., and Oshchepkov, S.: A new airborne polar Nephelometer for the measurements of optical and microphysical cloud properties, Part 1: Theoretical design, Ann. Geophys., 15, 451-459, doi:10.1007/s00585-997-0451-1, 1997.

Gayet, J.-F., Auriol, F., Minikin, A., Ström, J., Seifert, M., Krejci, R., Petzold, A., Febvre, G., and Schumann, U.: Quantitative measurement of the microphysical and optical properties of cirrus clouds with four different in situ probes: evidence of small ice crystals, Geophys. Res. Lett., 29, 2230, doi:10.1029/2001GL014342, 2002.

Gayet, J.-F., Ovarlez, J., Shcherbakov, V., Ström, J., Schumann, U., Minikin, A., Auriol, F., Petzold, A., and Monier, M.: Cirrus cloud microphysical and optical properties at southern and northern mid-latitudes during the INCA experiment, J. Geophys. Res., 109, D20206, doi:10.1029/2004JD004803, 2004.

Gayet, J.-F., Shcherbakov, V., Mannstein, H., Minikin, A., Schumann, U., Ström, J., Petzold, A., Ovarlez, J., and Immler, F.: Microphysical and optical properties of midlatitude cirrus clouds observed in the southern hemisphere during INCA, Q. J. Roy. Meteor. Soc., 132, 2719-2748, doi:10.1256/qj.05.162, 2006.

Gayet, J.-F., Mioche, G., Dörnbrack, A., Ehrlich, A., Lampert, A., and Wendisch, M.: Microphysical and optical properties of Arctic mixed-phase clouds. The 9 April 2007 case study., Atmos. Chem. Phys., 9, 6581-6595, doi:10.5194/acp-9-6581-2009, 2009.

Grenfell, T. C. and Warren, S. G.: Representation of a nonspherical ice particle by a collection of independent spheres for scattering and absorption of radiation, J. Geophys. Res., 104, 3169731709, doi:10.1029/1999JD900496, 1999.

Heymsfield, A. J.: On measurements of small ice particles in clouds, Geophys. Res. Lett., 34, L23812, doi:10.1029/2007GL030951, 2007.

Inoue, T.: On the temperature and effective emissivity determination of semi-transparent cirrus clouds by bi-spectral measurements in the 10 um window region, J. Meteorol. Soc. Jpn., 63, 88-98, 1985.

King, M. D., Platnick, S., Wind, G., Arnold, G. T., and Dominguez, R. T.: Remote sensing of radiative and microphysical properties of clouds during TC4: results from MAS, MASTER, MODIS, and MISR, J. Geophys. Res., 115, 857-875, doi:10.1029/2009JD013277, 2010.

Knollenberg, R. G.: Three new instruments for cloud physics measurements: the 2-D spectrometer, the forward scattering spectrometer probe, and the active scattering aerosol spectrometer, Preprints, Int. Conf. on Cloud Physics, 1976.

Korolev, A. and Isaac, G. A.: Shattering during Sampling by OAPs and HVPS, Part 1: Snow particles, J. Atmos. Ocean. Tech., 22, 528-542, doi:10.1175/JTECH1720.1, 2005.
Lawson, R. P. and Baker, B. A.: Improvement in determination of ice water content from two-dimensional particle imagery, Part 2: Applications to collected data, J. Appl. Meteorol. Clim., 45, 1291-1303, doi:10.1175/JAM2399.1, 2006.

Lawson, R. P., Baker, B. A., Schmitt, C. G., and Jensen, T. L.: An overview of microphysical properties of Arctic clouds observed in May and July 1998 during FIRE ACE, J. Geophys. Res, 106, 14989-15014, 2001.

L'Ecuyer, T. S., Gabriel, P., Leesman, K., Cooper, S. J., and Stephens, G. L.: Objective assessment of the information content of visible and infrared radiance measurements for cloud microphysical property retrievals over the global oceans, Part 1: Liquid clouds, J. Appl. Meteorol. Clim., 45, 20-41, doi:10.1175/JAM2326.1, 2006.

Liou, K.: Influence of cirrus clouds on weather and climate processes: a global perspective, Mon. Weather Rev., 114, 11671199, 1986.

Lohmann, U. and Roeckner, E.: Influence of cirrus cloud radiative forcing on climate and climate sensitivity in a general circulation model, J. Geophys. Res.-Atmos., 100, 16305-16323, 1995.

Lynch, D., Sassen, K., Starr, D. O., and Stephens, G. L.: Cirrus, Oxford University Press, 2002.

Marks, C. J. and Rodgers, C. D.: A retrieval method for atmospheric composition from limb emission measurements, J. Geophys. Res., 98, 14939-14953, doi:10.1029/93JD01195, 1993.

Marquardt, D. W.: An algorithm for least-squares estimation of nonlinear parameters, SIAM J. Appl. Math., 11, 431-441, 1963.

McFarquhar, G. M., Zhang, G., Poellot, M. R., Kok, G. L., McCoy, R., Tooman, T., Fridlind, A., and Heymsfield, A. J.: Ice properties of single-layer stratocumulus during the mixed-phase Arctic cloud experiment: 1. Observations, J. Geophys. Res., 112, D24201, doi:10.1029/2007JD008633, 2007.

Miller, S. D., Stephens, G. L., Drummond, C. K., Heidinger, A. K., and Partain, P. T.: A multisensor diagnostic satellite cloud property retrieval scheme, J. Geophys. Res., 105, 19955-19971, doi:10.1029/2000JD900273, 2000.

Mioche, G., Josset, D., Gayet, J.-F., Pelon, J., Garnier, A., Minikin, A., and Schwarzenboeck, A.: Validation of the CALIPSO-CALIOP extinction coefficients from in situ observations in midlatitude cirrus clouds during the CIRCLE-2 experiment, J. Geophys. Res., 115, D00H25, doi:10.1029/2009JD012376, 2010.

Mitchell, D. L.: Effective diameter in radiation transfer: General definition, applications, and limitations, J. Atmos. Sci., 59, 23302346, 2002.

Parkinson, C. L. and Greenstone, R.: EOS Data Products Handbook, NASA Goddard Space Flight Center, Greenbelt, Maryland, 253 pp., 2000.

Parol, F., Buriez, J. C., Brogniez, G., and Fouquart, Y.: Information content of avhrr channel 4 and 5 with respect to the effective radius of cirrus cloud particles, J. Appl. Meteorol., 30, 973-984, 1991.

Raschke, E., Schmetz, J., Heintzenberg, J., Kandel, R., and Saunders, R.: The International Cirrus Experiment (ICE): a joint European effort, ESA J., 14, 193-199, 1990.

Rienecker, M., Suarez, M., Todling, R., Bacmeister, J., Takacs, L., Liu, H.-C., Gu, W., Sienkiewicz, M., Koster, R., Gelaro, R., Stajner, I., and Nielsen, E.: The GEOS-5 Data Assimilation System - Documentation of Versions 5.0.1, 5.1.0, and 5.2.0, Tech. 
Rep. 27, Technical Report Series on Global Modeling and Data Assimilation, 2008.

Rodgers, C. D.: Inverse Methods for Atmospheric Sounding: Theory and Practice, World Scientific Pub Co Inc, 2000.

Sassen, K. and Cho, B. S.: Subvisual-thin cirrus lidar dataset for satellite verification and climatological research, J. Appl. Meteorol., 31, 1275-1285, doi:10.1175/15200450(1992)031<1275:STCLDF> 2.0.CO;2, 1992.

Sauvage, L., Chepfer, H., Trouillet, V., Flamant, P. H., Brogniez, G., Pelon, J., and Albers, F.: Remote sensing of cirrus radiative parameters during EUCREX'94, case study of 17 April 1994, Part 1: Observations, Mon. Weather Rev., 127, 486-503, 1999.

Shannon, C. E. and Weaver, W.: The Mathematical Theory of Communication, University of Illinois Press, 1949.

Sourdeval, O., Brogniez, G., Pelon, J., C.-Labonnote, L., Dubuisson, P., Parol, F., Josset, D., Garnier, A., Faivre, M., and Minikin, A.: Validation of IIR/CALIPSO Level 1 measurements by comparison with collocated airborne observations during CIRCLE-2 and Biscay '08 campaigns, J. Atmos. Ocean. Tech., 29, 653-667, doi:10.1175/JTECH-D-11-00143.1, 2012.

Stephens, G. L.: Optical properties of eight water cloud types, Tech. Paper 36, Commonwealth Science and Industrial Research Organisation Division of Atmospheric Physics, 1979.

Stephens, G. L., S.-C. Tsay, P. W. Stackhouse, and P. J. Flatau.: The relevance of the microphysical and radiative properties of cirrus clouds to climate and climatic feedback, J. Atmos. Sci., 47, 1742-1754, 1990.

Vaughan, G., Schiller, C., Kenzie, A. R. M., Bower, K., Peter, T., Schlager, H., Harris, N. P. R., and May, P. T.: SCOUT-O3/ ACTIVE: High-altitude aircraft measurements around deep tropical convection, B. Am. Meteorol. Soc., 89, 647-662, 2005a.

Vaughan, M., Winker, D., and Powell, K. A.: CALIOP algorithm theoretical basis document, Part 2: Feature detection and layers properties algorithms, PC-SCI-202.02, NASA Langley Research Center, available at: http://www-calipso.larc.nasa.gov/resources/ project_documentation.php, 2005 b.
Vaughan, M., Powell, K., Kuehn, R., Young, S., Winker, D., Hostetler, C., Hunt, W., Liu, Z., McGill, M., and Getzewich, B.: Fully automated detection of cloud and aerosol layers in the CALIPSO lidar measurements, J. Atmos. Ocean Tech., 26, 2034-2050, 2009.

Walko, R. L., Cotton, W. R., Meyers, M. P., and Harrington, J. Y.: New RAMS cloud microphysics parameterization, Part 1: the single-moment scheme, Atmos. Res., 38, 29-62, 1995.

WCRP: A preliminary cloudless standard atmosphere for radiation computation, vol. WCP-112, International Association for Meteorology and Atmospheric Physics, 1986.

Wilber, A. C., Kratz, D. P., and Gupta, S. K.: Surface Emissivity Maps for Use in Satellite Retrievals of Longwave Radiation, Technical Publication 35, NASA Langley Research Center, 1999.

Winker, D. M., Hunt, W. H., and McGill, M. J.: Initial performance assessment of CALIOP, Geophys. Res. Lett., 34, 1211-1229, doi:10.1029/2007GL030135, 2007.

Winker, D. M., Pelon, J., Coakley, J. A., Ackerman, S. A., Charlson, R. J., Colarco, P. R., Flamant, P., Fu, Q., Hoff, R. M., Kittaka, C., Kubar, T. L., Le Treut, H., McCormick, M. P., Mégie, G., Poole, L., Powell, K., Trepte, C., Vaughan, M. A., and Wielicki, B. A.: The CALIPSO Mission: A global 3-D view of aerosols and clouds, B. Am. Meteorol. Soc., 91, 1211-1229, doi:10.1175/2010BAMS3009.1, 2010.

Worden, J. R., Bowman, K. W., and Jones, D. B.: Two-dimensional characterization of atmospheric profile retrievals from limb sounding observations, J. Quant. Spectrosc. Ra., 86, 45-71, 1999.

Yang, P., Wei, H., Huang, H. L., Baum, B. A., Hu, Y. X., Kattawar, G. W., Mishchenko, M. I., and Fu, Q.: Scattering and absorption property database for nonspherical ice particles in the near- through far-infrared spectral region, Appl. Optics, 44, 5512-5523, 2005.

Zhang, Y., Macke, A., and Albers, F.: Effect of crystal size spectrum and crystal shape on stratiform cirrus radiative forcing, Atmos. Res., 52, 59-75, 1999. 